\title{
Novel Permanent Magnet Tubular Linear Generator for Wave Energy Converters
}

\author{
Loránd Szabó, Claudiu Oprea, Ioan-Adrian Viorel, Károly Ágoston Biró \\ Department of Electrical Machines, Technical University of Cluj \\ P.O. Box 358, 400750 Cluj, Romania \\ E-mail: Lorand.Szabo@mae.utcluj.ro
}

\begin{abstract}
Clean and sustainable alternative energy is becoming attractive as oil costs rise and the negative side effects of traditional energy systems begin to become apparent. One often overlooked, but still rapidly growing alternative is wave power. There are fascinating new designs for harnessing the tremendous power of the waves. Hence any contribution in this field could be of real interest for numerous specialists. In the paper a novel modular permanent magnet tubular linear generator is proposed and analyzed by means of numeric field computations. It was designed for wave power take off systems to be placed in the Black Sea near the Romanian coasts.
\end{abstract}

Keywords-linear generators, marine energy converters, permanent magnet variable reluctance machines, renewable energy resources, wave energy.

\section{INTRODUCTION}

It is crucial for the mankind to develop clean renewable energy resources. We cannot indefinitely continue to base our life on the consumption of finite energy resources, as those based on fossil fuels and nuclear power. These sources of energy will not last forever and have proven to be one of the main causes of all the environmental problems.

Renewable sources of energy are in line with an overall strategy of sustainable development. They help reduce the dependence of energy imports, and also help improve the competitiveness of industries and have a positive impact on regional development and employment [1].

Renewable energy sources include hydropower, biomass, solar, wind, geothermal, and ocean energy. The rapid deployment of renewable energy technologies and their larger development in the near future, raise challenges and opportunities regarding their integration into energy supply systems.

Together the renewable energy sources currently contribute the equivalent of 7\% of the World's primary energy use. Day by day the share of renewable energy in electricity consumption is increased. For this the EU has set a target of $12 \%$ by 2010 . As a result of the political commitments the renewable energy industry is developing around the world being one of the highest priorities of mankind.

To these trends Romania also had been aligned in 2002 according to the medium-term National Strategy for the power sector. In this is pointed out as the main future objectives are to develop efficient energy markets, to ensure higher quality and security of supply and to comply with EU standards regarding the rational use of energy and environment protection.

\section{ENERGY FROM WAVES}

Ocean energy is a yet unexploited renewable energy source on our planet. Preliminary surveys show that marine power has a potential to supply a significant part of the future European energy needs [2].

The ocean energy technologies have been around for decades, but for a variety of reasons (including rising oil prices, technological advancements and the sheer grit of a handful of pioneer developers), ocean energy has made a huge splash only in the last years [3].

The three most well developed technologies for deriving electrical power from the ocean include tidal power, wave power and ocean thermal energy conversion. From these possibilities the wave energy conversation seems to have the greatest general application.

Oceanic waves are generally considered to be a concentrated form of solar energy. Waves are produced by winds that are created by pressure differences in the Earth's atmosphere, which are created by differential solar heating. The energy transferred from wind to water is in the form of potential energy (mass of water in wave above sea level) and kinetic energy (movement of water molecules). The amount of energy transferred is dependent upon the wind speed, the amount of time that the wind is blowing and the distance over which it travels [4].

The World Energy Council (WEC) has estimated the global ocean wave energy over $2 \mathrm{TW}$ (which means $17,500 \mathrm{TWh} /$ year). From this it has been estimated that the practical economic contribution of the wave energy converters could be 2,000 TWh/year, similar to current installed nuclear or hydroelectric generation capacity. About $95 \%$ of this power potential is offshore, the rest being on the shoreline or nearshore. Of course all of it is not practical, but if any amount could be harnessed, it could mean a huge quantity of cleanly produced energy.

Such generating capacity could result in up to 2 billion tones of $\mathrm{CO}_{2}$ emissions being displaced from fossil fuel generation per year, similar to current emissions from electricity generation in the US [4]. 
There are also several other compelling arguments for using the wave energy technology [5]:

i.) By its high power density it is one of the lowest cost renewable energy sources.

ii.) The wave energy is more predictable than solar and wind energy, offering a better possibility of being dispatched to an electrical grid system.

iii.) The conversion of ocean wave energy to electricity is believed to be one of the most environmentally benign ways to generate electricity, hence it does not render any waste that has to be stored or destroys the environment.

iv.) The wave energy conversion devices can be located far enough away from the shore (offshore) that they are generally not visible.

Although waves represent a free and clean source of energy, capturing this energy inevitably needs large capital investments and can have some impacts on the environment, which must be taken also into account [6].

The potential wave power can be converted to electricity via mechanical means. The wave power take off systems are often called also marine energy converters (MECs). Harnessing the energy provided by oceanic waves has been developed for over the past thirty years via numerous technologies [6].

Such systems can be offshore and onshore. The offshore ones are situated in deep water. Often sophisticated mechanisms use the bobbing motion of the waves to power a pump that creates electricity. Other offshore devices use the rise and fall of the float to generate electrical power. The onshore systems, built along shorelines, extract the energy of breaking waves.

In both type of wave power take off systems the most complicated constructions are with direct mechanical linkage, with pneumatic (for example the Oscillating Water Column system [7]) or with hydraulic systems (as Pelamis [8]).

More simple are the direct driven power take off systems, which have the electrical generator and moving part of the device (a floating buoy on the surface of the sea) joined directly together with no intermediate mechanical systems.

Several recent technical reports concluded that generation of electricity from wave energy may be economically feasible in the near future and as such, warrants continued investigation [5]. This was the main reason why our research team begun to study the possibilities of placing wave energy based power plants near the Romanian shore of the Black Sea [9].

\section{WAVE ENERgy CONVERTERs For THE BLACK SEA}

The power potential for waves can be described as units of power per meter of wave crest length. The greatest power in the wave fronts is about $100 \mathrm{~kW} / \mathrm{m}$ in the Atlantic Ocean South-West of Ireland, the Southern Ocean and off Cape Horn [8].

Large portions of the world's potential wave energy resources are found in sheltered waters and calmer seas, which often exhibit a milder, but still steady wave climate. Examples are the Baltic, the Mediterranean and the Black Sea [10].
Unfortunately it was clear from the very beginning that the wave power in the Black Sea is moderate. Precise data regarding the wave energy potential in the Black Sea near the Romanian coasts could not be found in any available bibliographical resources.

Therefore our research team was constrained to look for indirect information on the wave energy potential from other similar sheltered seas and on other available parameters of the waves in the Black Sea.

The results of this study showed that the computed wave power density in the Black Sea near the Romania coast is the highest during winter and autumn, fortunately coinciding with the greatest energy demands. The mean value of the power density was found out to be about of $1 \mathrm{~kW} / \mathrm{m}$.

This low power density is compensated by relatively small wave power variability as compared with the seas with high wave power densities. Finally it was pointed out that taking into account the various advantages of the electrical power generation from waves also at this relatively small wave energy potential the exploitation of the wave energy could be of real interest [11].

The simplest direct driven power take off system was proposed to be used in the future wave power plant. It consists of a floating buoy lifted-dropped by the waves connected directly to the linear generator fixed on a concrete foundation, which stands on the bottom of the sea (as shown in Fig. 1) [12].

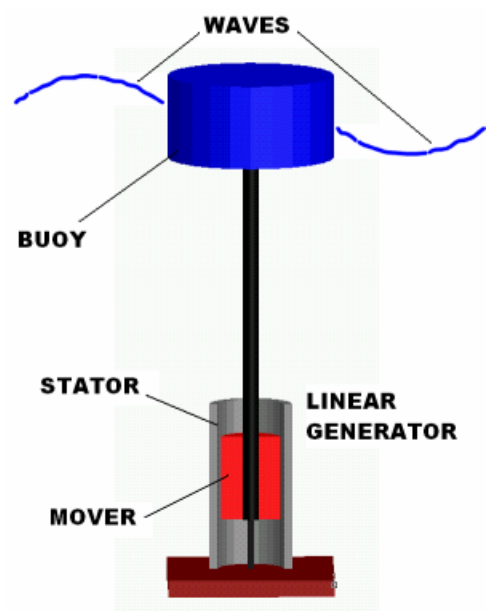

Fig. 1. The floating buoy system with the linear generator

The power take off system works upon the difference in height between wave top and wave bottom. Hence the mover of the linear generator connected to the buoy is permanently in motion generating electrical power [7].

By optimizing the shape and operation of the buoy up to $90 \%$ absorption efficiency can be achieved with such devices [13].

The proposed wave energy converter can be configured in many different ways in order to best fit its performances to the requirements and to the given environmental conditions.

The variable wave heights highlight one of the difficulties with such wave energy converters, namely the requirement of 
adaptability to different sea states. A device which is optimized for a given amplitude and frequency must be capable of surviving also in much rougher conditions.

Between the generator and the gird ac/dc, respectively dc/ac converters must be coupled, as shown in Fig. 2. The electric power is proposed to be transported via a dc net to the land, where practically the connection to the grid will be done.

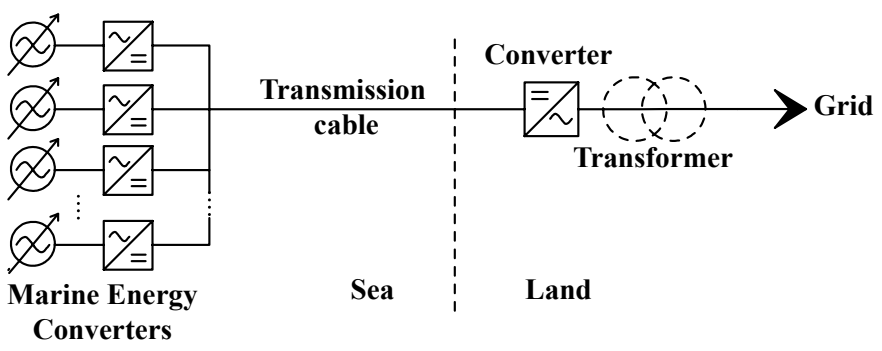

Fig. 2. The proposed power system

The above presented electric system is only one of the numerous possible structures, and it was selected based on the specific circumstances regarding the placement and the power of the marine energy converter near the Romanian shore of the Black Sea.

Anyway the crucial part of such marine renewable energy devices is the efficient conversion of kinetic energy into electrical energy. In the proposed wave energy take off system this is done by high efficiency linear generators.

\section{LINEAR GENERATORS FOR WAVE ENERGY CONVERTERS}

Linear generators can extract the power of the waves in the form of a reciprocating motion at low speed. Direct extraction of this low speed, high torque energy is possible, but the electrical output (voltage) will need some electronic processing of the waveform to enable grid connection.

Hence the optimal design of the linear generator used in such a system is critical in the development of the entire wave power plant.

In the literature mainly the following linear generators are proposed for wave energy converting power plants:

i.) Linear permanent magnet synchronous machines, both with surface and buried permanent magnets [14].

ii.) Vernier hybrid linear machines [15], [16].

iii.) Air cored permanent magnet tubular linear machines [6], [17].

The descriptions and the performances of the above mentioned machines had been studied from the point of view of their applicability in the power plants intended to be placed in the Black Sea.

The main features of the linear generators to be applied here were determined upon the characteristics of the waves in this area of the Black Sea:

i.) power of a few $\mathrm{kWs}$,

ii.) speed up to $1 \mathrm{~m} / \mathrm{s}$ iii.) strokes under $1 \mathrm{~m}$.

Of course as these linear generators are under the water in hard to mount and to access places they have to be maintenance free and to have great force density in order to have as low mass and volume as possible.

Due to these characteristics it was clear that only permanent magnet excited machines could be used, because they do not need extra sources for excitation and do not have hard to maintain brushes. The displacement of the generator being short the best solution was to use tubular machines, which require the simplest bearings from all the linear machines and have high power density. As they work at very low speeds special design had to be applied.

At the beginning our research team focused on two variants of the permanent magnet tubular linear generator: with an air cored and with an iron cored stator variant. In both cases the mover of the machine was identical.

The comparison of the two variants was made upon the results of numeric field computations [11]. As it was stated out each variant had its advantages and drawbacks. The linear generator having ironless stator obviously had a simpler and cheaper construction and the induced voltage in its winding had nearly a sinusoidal shape.

On the other hand in the iron-cored variant the magnetic fluxes generated by the permanent magnets placed in the mover were much more better concentrated inside the windings resulting in about 3 times higher voltage generated as in the case of the air cored variant [11]. A disadvantage of this variant is that the induced voltage has important harmonic content due to the non-linearity of the iron core surrounding the windings. But this drawback in the certain application in discussion it is not very significant, because the windings of the generator are not connected directly to the grid. The power electronic devices connected between it and the grid can correct the waveform of the induced voltage in order not to introduce perturbations in the network.

Therefore our research team dealt only with tubular permanent magnet linear generators having iron cored stator.

Based on the previous experiences and the given requirements a novel permanent magnet tubular linear generator was designed and analyzed. Its main structure is given in Fig. 3.

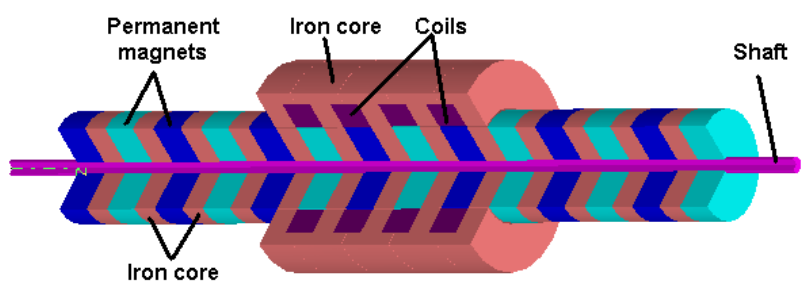

Fig. 3. The structure of the proposed linear generator

The mover of the tubular generator in study consists of iron core rings fixed on a shaft alternated with permanent magnet rings magnetized in radial direction. The permanent magnets have alternated magnetization. Hence strong magnetic flux is generated outside the moving armature. 
In the outer part of the linear generator the winding and the stator iron core is placed. This part of the generator is built up modularly in order to easy adapt the construction to different working conditions.

Each module has a ring type iron core having U-shaped cross-section, as it can be seen in the half cross section of the machine in Fig. 4.

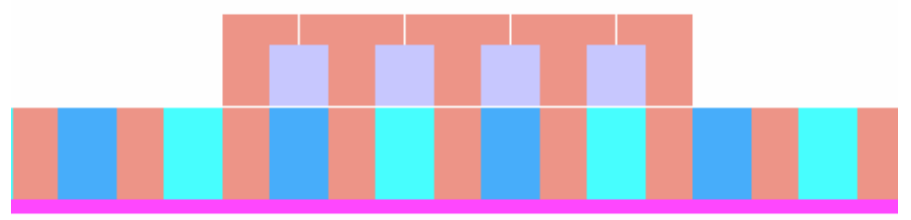

Fig. 4. Cross-section of the proposed linear generator

Inside the iron core is placed the coil. To be able to manufacture the stator of the generator the iron core is built up of two separate pieces. The air-gap between the two subassemblies can be also observed in Fig. 4.

By placing and coupling different number of modules various output voltages and different phase numbers can be obtained. In the structure given in the previous figures four coils are coupled together forming a single phase of the machine. Mounting three correctly shifted such stators together a three-phase generator can be built up.

By moving the armature with the permanent magnets inside the linear generator a varying magnetic flux will pass through the winding, generating emf. This can be collected on the terminals of the windings.

The main characteristics of the linear generators in study were obtained via precise numeric field computations. For this purpose the JMAG finite elements method based software package was used [18].

In order to reduce at this stage of the researches the time of the simulations the 2D axial symmetric transient analyses of the proposed linear generators was performed.

The mesh generated automatically by the program over the half cross section of the linear generator is given in Fig. 5.

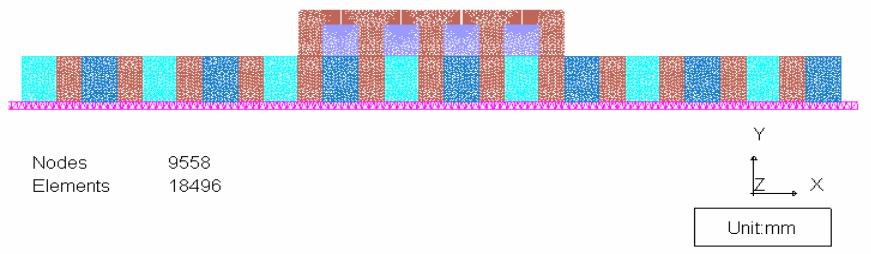

Fig. 5. The generated mesh

Next the main results obtained via the field computations will be given. At first the obtained field lines are shown. In all the figures only the field lines inside the machine are plotted.

As a transient analysis was performed in order to obtain the induced voltages in the winding the field computations were obtained in numerous relative positions of the mover. The mover was displaced with a $1 \mathrm{~m} / \mathrm{s}$ constant speed.
Here, in Fig. 6, only the field lines in two distinctive positions of the mover will be given: when the stator poles are aligned, respectively perfectly un-aligned with the iron core rings of the mover.

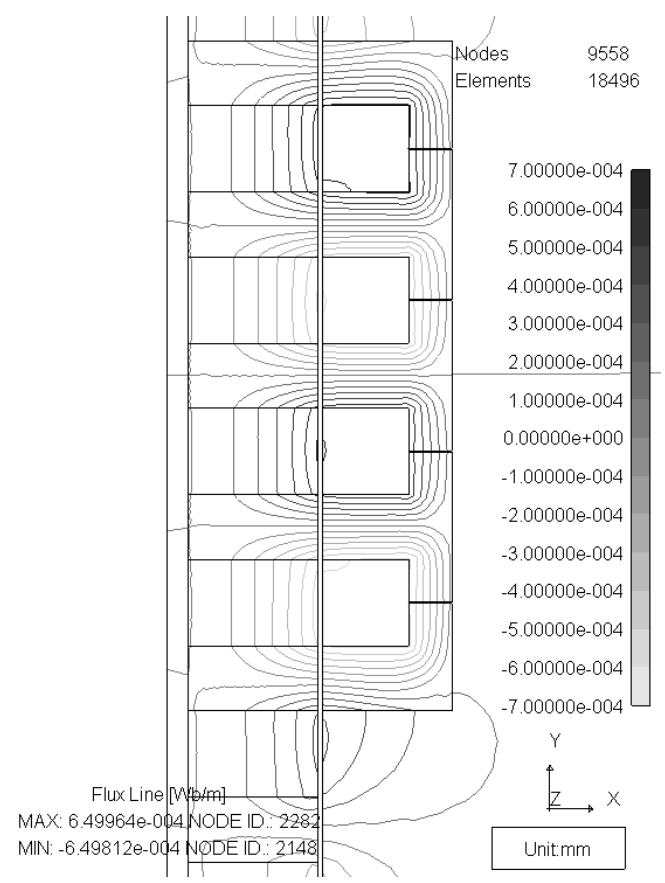

a) aligned position

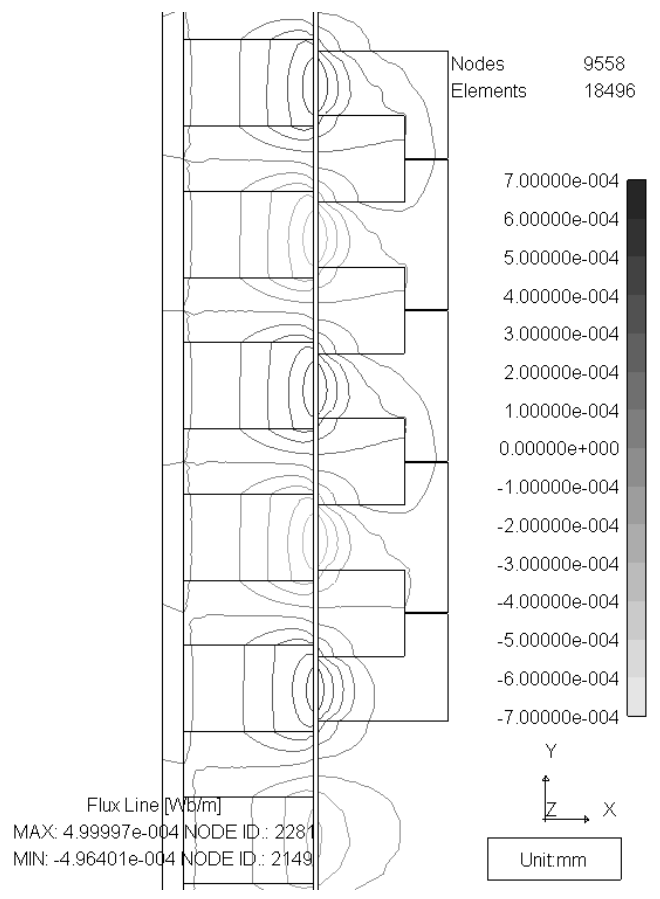

b) un-aligned position

Fig. 6. The field lines obtained via field computations

It can be easy seen from the plots of the field lines that the change of the magnetic flux inside the coils during the movement of the armature is significant. Therefore also the induced voltage in the windings is expected to be enough great. 
Next the computed induced voltage in the winding (the four coils connected in series) of the linear generator taken into study is given in Fig. 7.

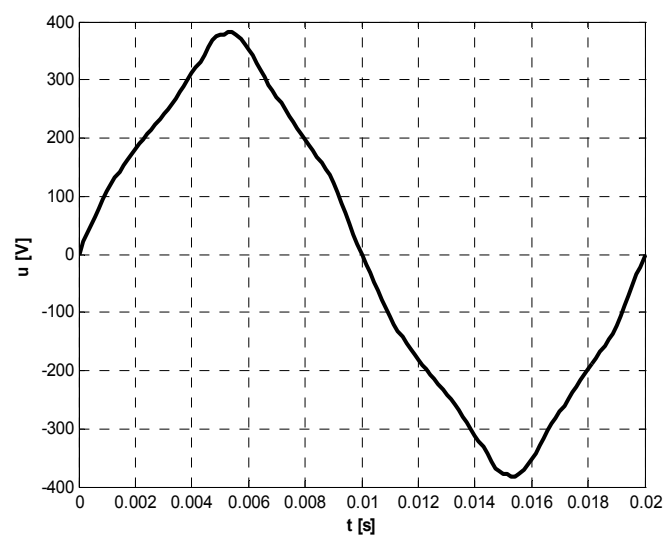

Fig. 7. The induced voltages in the winding

As it can be seen in Fig. 7 the obtained voltage has both its amplitude and frequency very closed to that given in the initial design data $(380 \mathrm{~V}$, respectively $50 \mathrm{~Hz})$.

The induced voltage in the linear generator in study has significant harmonic content, as it was pointed out previously.

\section{CONCLUSIONS}

All the obtained results emphasize the correct concept of the proposed linear generators and the advantages of using iron cored tubular linear generator constructions for such applications.

By minor changes in the design both the frequency and the amplitude of generated voltages can be changed in a manner as to fit to any requirements of the power electronic devices connected together or to the wave conditions (amplitude and speed) of the location where the power take off system will be placed.

In the future the analysis has to be extended also for sinusoidal variation of the speed, in order to simulate the real movement of the linear generator imposed by the buoy's displacement on the sea surface. Also the control and the power system of the proposed marine power converter have to be designed.

The promising results will stimulate the members of our research team to deepen understanding in this field and to obtain more and better results of interest for all the specialist working in this field.

\section{ACKNOWLEDGMENT}

The work was possible due to the support given by the Romanian National Council of Scientific Research in Higher Education under grant A1305/2006 entitled "Linear Generators for Power Plants Using Renewable Wave Energy". The authors should like to sincerely thank this way for the financial support.
We also should like to thank to POWERSYS (France) for offering us a full-working trial of the JMAG electromagnetic field analysis software.

\section{REFERENCES}

[1] "On Activities to Ensure Global Energy Security: Recommendations of the Energy Safety Group to the G8 Summit Civil G8 International NGO Forum," Moscow (Russia), 2006, URL: http://www.g7.utoronto.ca /summit/2006stpetersburg/civil8/cg8060310-energy.html.

[2] Callaghan, J., "Future Marine Energy Results of the Marine Energy Challenge: Cost competitiveness and growth of wave and tidal stream energy," Research Report, Carbon Trust, London (UK), 2006. URL: http://oreg.ca/docs/Carbon\%2Trust\%20Report/FutureMarineEnergy.pdf.

[3] Elefant, C., and O'Neill, S., "Ocean Energy Report for 2005," OREC (Ocean Renewable Energy Coalition), 2006. URL: http://www. renewableenergyaccess.com/rea/news/story?id=41396.

[4] Thorpe, T.W., "An Overview of Wave Energy Technologies" Report AEAT-3615, Office of Science and Technology, AEA Technology, 1999.

[5] Previsic, M., Bedard, R., and Hagerman, G., "Offshore Wave Energy Conversion Devices," Electric Power Research Institute (EPRI) Report no. WP 004 US, Palo Alto (USA), 2004.

[6] Baker, N.J., "Linear Generators for Direct Drive Marine Renewable Energy Converters," Ph.D. Thesis, School of Engineering, University of Durham (UK), 2003.

[7] Leijon, M, "Multi-Physics Simulation of Wave Energy to Electric Energy Conversion by Permanent Magnet Linear Generator," IEEE Transactions on Energy Conversion, vol. 20 (March 2005), no. 1, pp. 219-224.

[8] "2004 Survey of Energy," World Energy Council, London (UK), 2004.

[9] Szabó, L., and Oprea, C., "Linear Generators for Wave Power Plants to Be Set up Near the Romanian Coasts of the Black Sea," Oradea University Annals, Electrotechnical Fascicle, Computer Science and Control Systems Session, Oradea (Roamnia), 2006, pp. 120-125.

[10] Bernhoff, H., Sjöstedt, E., and Leijon, M., " Wave energy resources in sheltered sea areas: A case study of the Baltic Sea," Proceedings of the $5^{\text {th }}$ European Wave Energy Conference, Cork (Ireland), 2003.

[11] Szabó, L., and Oprea, C., "Wave Energy Plants for the Black Sea Possible Energy Converter Structures," Proceedings of the International Conference on Clean Electrical Power (ICCEP '2007), Capri (Italy), paper no. E3184, 2007.

[12] Mueller, MA, et al., "Low Speed Linear Electrical Generators for Renewable Energy Applications," Proceedings of the Conference on Linear Drives in Industrial Applications (LDIA '2003), Birmingham (UK), pp. 121-124, 2003.

[14] Yokobori, K., "Survey of Energy Resources," $19^{\text {th }}$ edition, World Energy Council, Tokyo (Japan), 2002.

[15] Danielsson, O., Thorburn, K., Eriksson, and M., Leijon, M., "Permanent magnet fixation concepts for linear generator," Proceedings of the $5^{\text {th }}$ European Wave Energy Conference, Cork (Ireland), pp. 117-124, 2003.

[16] Mueller, M.A. et al., "Dynamic Modelling of a Linear Vernier Hybrid Permanent Magnet Machine Coupled to a Wave Energy Emulator Test Rig," Conference Record of the International Conference on Electrical Machines (ICEM '2004), Cracow (Poland), on CD: 495.pdf, 2004.

[17] Brooking, P.R.M., "Power conversion in a low speed reciprocating electrical generator," Conference Record of the International Conference on Electrical Machines (ICEM 2002), Brugge (Belgium), on CD: 452.pdf, 2002.

[18] "JMAG-Studio 8.4 Tutorial," JRI Solutions, Ltd., Engineering Technology Division, Tokyo (Japan), 2006. 